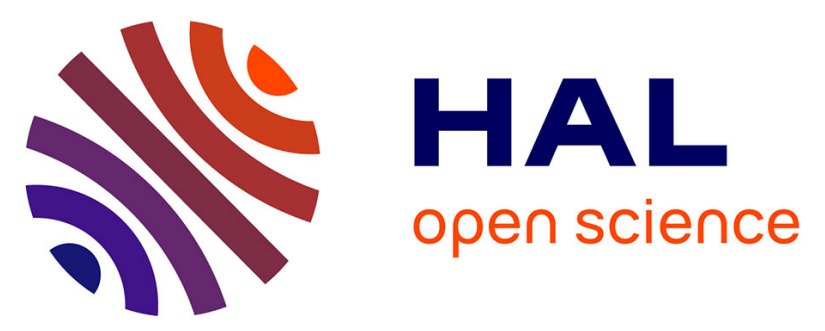

\title{
Particle reworking and solute transport by the sediment-living polychaetes Marenzelleria neglecta and Hediste diversicolor
}

Jenny Elisabet Hedman, Jonas S. Gunnarsson, Göran Samuelsson, Franck

Gilbert

\section{To cite this version:}

Jenny Elisabet Hedman, Jonas S. Gunnarsson, Göran Samuelsson, Franck Gilbert. Particle reworking and solute transport by the sediment-living polychaetes Marenzelleria neglecta and Hediste diversicolor. Journal of Experimental Marine Biology and Ecology, 2011, vol. 407, pp. 294-301. 10.1016/j.jembe.2011.06.026 . hal-00780265

\section{HAL Id: hal-00780265 https://hal.science/hal-00780265}

Submitted on 23 Jan 2013

HAL is a multi-disciplinary open access archive for the deposit and dissemination of scientific research documents, whether they are published or not. The documents may come from teaching and research institutions in France or abroad, or from public or private research centers.
L'archive ouverte pluridisciplinaire HAL, est destinée au dépôt et à la diffusion de documents scientifiques de niveau recherche, publiés ou non, émanant des établissements d'enseignement et de recherche français ou étrangers, des laboratoires publics ou privés. 


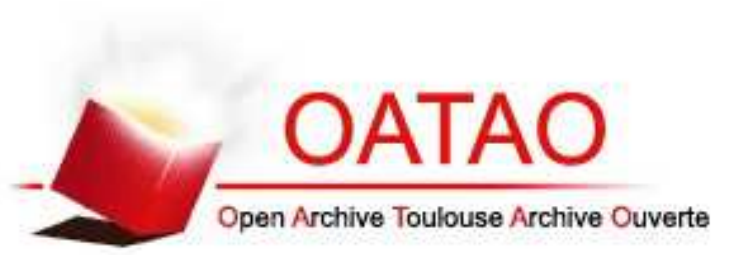

\section{Open Archive Toulouse Archive Ouverte (OATAO)}

OATAO is an open access repository that collects the work of Toulouse researchers and makes it freely available over the web where possible.

This is an author-deposited version published in: http://oatao.univ-toulouse.fr/ Eprints ID: 6081

To link to this article: DOI: $10.1016 /$ j.jembe.2011.06.026

URL: http://dx.doi.org/10.1016/j.jembe.2011.06.026

To cite this version: Hedman, Jenny Elisabet and Gunnarsson, Jonas S. and Samuelsson, Göran and Gilbert, Franck Particle reworking and solute transport by the sediment-living polychaetes Marenzelleria neglecta and Hediste diversicolor. (2011) Journal of Experimental Marine Biology and Ecology, vol. 407 (n²). pp. 294-301. ISSN 0022-0981 


\title{
Particle reworking and solute transport by the sediment-living polychaetes Marenzelleria neglecta and Hediste diversicolor
}

\author{
Jenny E. Hedman ${ }^{\mathrm{a}, *, 1}$, Jonas S. Gunnarsson ${ }^{\mathrm{a}}$, Göran Samuelsson ${ }^{\mathrm{a}}$, Franck Gilbert ${ }^{\mathrm{b}, \mathrm{c}}$ \\ a Department of Systems Ecology, Stockholm University, S-10691 Stockholm, Sweden \\ ${ }^{\mathrm{b}}$ Université de Toulouse, INP, UPS, EcoLab (Laboratoire Ecologie Fonctionnelle et Environnement), 118 Route de Narbonne, 31062 Toulouse, France \\ c CNRS, EcoLab, 31062 Toulouse, France
}

Keywords:

Baltic Sea

Bioirrigation

Bioturbation

Contaminant

Nereis diversicolor

Nutrient

\begin{abstract}
A B S T R A C T
This experimental study quantified and compared particle-mixing and solute transport by the polychaetes Marenzelleria neglecta (2 g ww, 3200 ind. $\mathrm{m}^{-2}$ ) and Hediste diversicolor $\left(2 \mathrm{~g} \mathrm{ww}, 800\right.$ ind. $\mathrm{m}^{-2}$ ) in Baltic Sea sediments. Particle tracers (luminophores) were added to the sediment surface and their vertical distribution in the sediment was measured after $10 \mathrm{~d}$. The rate of particle mixing was quantified using a gallery-diffusion model calculating the biodiffusion coefficient $D_{b}$ and the non-local transport parameter $r$. Bioirrigation was measured by adding an inert solute tracer (bromide) to the overlying water 1, 1.5 and $2 \mathrm{~d}$ before the end of the experiment, and quantified by calculating the net bromide flux and fitting the bromide profiles to a 1D diffusion model providing an apparent biodiffusion coefficient $D_{a}$. The two polychaete worms displayed similar particle-mixing and solute transport efficiencies (based on total biomass) despite different modes of bioturbation. However, $H$. diversicolor was a more efficient particle-reworker and $M$. neglecta a more efficient bioirrigator, on an individual level. $H$. diversicolor buried a higher percentage (13\%) of luminophores below the top $0.5 \mathrm{~cm}$ surface layer than $M$. neglecta $(6 \%)$. $D_{b}$ did not differ between the two species $\left(2.4 \times 10^{-3} \mathrm{~cm}^{2} \mathrm{~d}^{-1}\right)$ indicating a similar rate of diffusive mixing of the top sediment, however, the nonlocal transport parameter $r$ was $2.5 \mathrm{y}^{-1}$ for H. diversicolor and zero for M. neglecta, suggesting no significant particle-transport below the biodiffusive layer by $M$. neglecta. The average individual net bromide fluxes obtained were ca. $0.01 \mathrm{~mL} \mathrm{~min}^{-1}$ for $H$. diversicolor and $0.003 \mathrm{~mL} \mathrm{~min}{ }^{-1}$ for $M$. neglecta, corresponding to an area-specific rate of ca. $12 \mathrm{~L} \mathrm{~m}^{-2} \mathrm{~d}^{-1}$ at the used densities. $D_{a}$ did not differ between the two polychaetes, suggesting a higher individual solute exchange efficiency of $M$. neglecta considering the much higher ventilation rates reported for $H$. diversicolor than for Marenzelleria sp. The ongoing colonization of Baltic Sea sediments by M. neglecta at high densities may thus lead to an enhanced soluble release of both nutrients and contaminants. These results add information to the understanding of the potential effects of the invasion of M. neglecta on sediment biogeochemistry when competing with and/or replacing native species.
\end{abstract}

\section{Introduction}

Benthic invertebrates play a key role in sustaining important aquatic ecosystem functions at the sediment-water interface. Bioturbation (i.e. particle reworking and bioirrigation) by benthic organisms mix and transport particles and solutes in the upper sediment layer and across the sediment surface, triggering organic matter mineralization, nutrient regeneration and trace element cycling (Aller, 2001; Kristensen and Hansen, 1999). The effects of bioturbation on sediment biogeochemistry have been shown to be highly species-specific, and can be linked to particular feeding and burrowing strategies (Francois

\footnotetext{
* Corresponding author. Tel.: + 468 51954274; fax: + 46851954256.

E-mail address: jenny.hedman@nrm.se (J.E. Hedman).

1 Present address: Department of Contaminant Research, Swedish Museum of Natural History, Box 50007, S-10405 Stockholm, Sweden.
}

et al., 2002; Quintana et al., 2007). It is therefore of interest to characterize and quantify the bioturbation efficiency of individual species for a better prediction and understanding of processes such as cycling of nutrients and contaminants in the sediment compartment.

The brackish Baltic Sea, owing to its relatively young age and strong salinity gradient, has low species diversity and is hence particularly vulnerable to the invasion of new species (Leppäkoski et al., 2002). Since the 1980s, three sibling species of the polychaete genus Marenzelleria (Polychaeta, Spionidae) have successfully established themselves in the Baltic Sea and completely changed the benthic community structure in many areas (Orlova et al., 2006). Ecological implications of this invasion are still not well understood, although several studies have suggested a changed nutrient and contaminant dynamics in areas now dominated by Marenzelleria spp. (Hedman et al., 2008; Hietanen et al., 2007). Marenzelleria spp. are surface deposit-feeders creating J-shaped mucus-lined burrows down to $15 \mathrm{~cm}$ or more (Zettler et al., 1995). In the Baltic Sea they inhabit both 
shallow sandy substrates as well as deeper more muddy sediments at abundances ranging from a few hundred individuals per $\mathrm{m}^{2}$ up to 39000 ind.per $\mathrm{m}^{2}$ (Kube et al., 1996). There is little information available on the mode and efficiency of bioturbation by the three Marenzelleria species. Quintana et al. (2007) quantified particle reworking and bioirrigation by $M$. viridis, and showed that it transported both particles and solutes into the sediment more efficiently than the polychaete Heteromastus filiformis. Recently, they also described the mechanistic mode of burrow ventilation by M. viridis (Quintana et al., 2011). Experimental studies on the effect of bioturbation by Marenzelleria neglecta on the fate of contaminants (Granberg et al., 2008; Hedman et al., 2008) have suggested little mixing of sediment particles but an important transport of solutes (i.e. little transport of particle-associated contaminants compared to dissolved contaminants).

In shallow coastal areas Marenzelleria spp. are competing with the common ragworm Hediste diversicolor (Polychaeta, Nereidae). $H$. diversicolor inhabits muddy to sandy sediments down to ca. $15 \mathrm{~m}$ depth at densities ranging from 40 to 5000 ind. $\mathrm{m}^{-2}$ (Rasmussen, 1973). They are opportunistic omnivores, although their main feeding strategies are surface-deposit and filter feeding (Scaps, 2002). $H$. diversicolor lives in more or less permanent $\mathrm{U}$ or $\mathrm{Y}$-shaped burrows, creating a complex network of burrows extending down to ca. $15 \mathrm{~cm}$ (Davey, 1994). Based on the reworking of tracer particles, H. diversicolor has been classified as a "gallery-diffusor", which describes a combination of apparent biodiffusion in the upper sediment layer, with a non-local transport in deeper sediment (Francois et al., 2002). They are known to actively ventilate their burrow, increasing the flux of oxygen and nutrients over the sediment-water interface (Kristensen and Hansen, 1999). However, there is a lack of information on their bioirrigation efficiency using inert solute tracers.

The aim of this study was to quantify and compare the rate of particle-mixing and solute transport by $M$. neglecta and $H$. diversicolor in Baltic Sea sediment, with the hypothesis that $H$. diversicolor is a more efficient bioturbator. This is important information for the understanding of the potential effects of the invasive Marenzelleria spp. on Baltic Sea sediment functioning. We conducted a laboratory experiment where we added inert solute (bromide) and particle (luminophores) tracers to sediment tube cores and measured their transport into the sediment due to the worms' activities. Experimental results of the luminophore distributions were then applied in a gallery-diffusion model (Francois et al., 2002) to quantify the intensity of particle-reworking by these two polychaetes. Bioirrigation was quantified as the net flux of bromide transported at the sedimentwater interface and by fitting the experimentally derived bromide profiles to a 1D diffusion model.

\section{Materials and methods}

\subsection{Sediment and animal collection}

Sediment and animals were collected on April 23, 2007 at Mörkö $\left(59^{\circ} 2.29^{\prime} \mathrm{N}, 17^{\circ} 41.45^{\prime} \mathrm{E}\right)$, in the Stockholm Archipelago. Worms, both $H$. diversicolor and $M$. neglecta, were collected with a shovel from $1 \mathrm{~m}$ depth and sieved out on-site with a $1 \mathrm{~mm}$ mesh. The three sibling species of Marenzelleria found in the Baltic Sea (M. neglecta, M. viridis, $M$. arctia) are morphologically very similar and can only be determined accurately to the species level using molecular genetic tools (Blank et al., 2008), which was not done in this study. However, based on earlier mapping of the species distribution by Blank et al. (2008), it is most likely that the species used in this experiment was $M$. neglecta. Sediment and water (ca. $6.5 \mathrm{psu}$ ) were collected from the same site and transported together with the worms to the lab. Worms were kept in their natural sediment in a climate room at ca. $10{ }^{\circ} \mathrm{C}$ until the start of the experiment. Sediment was sieved through a
Table 1

Sediment characteristics. Total carbon (TC) and nitrogen (TN) contents of the sediment (\% dry wt), $n=3$. Average \pm STD.

\begin{tabular}{lllll}
\hline & TC $(\%)$ & TN $(\%)$ & Porosity & Grain size \\
\hline Sediment & $0.10 \pm 0.01$ & $0.01 \pm 0.00$ & $0.41 \pm 0.02$ & Sandy \\
\hline
\end{tabular}

$1 \mathrm{~mm}$ sieve to remove macrofauna and left to compact in $20 \mathrm{~L}$ buckets with a layer of aerated water on top.

The geochemical characteristics of the sediment are presented in Table 1. Total carbon (TC) and nitrogen (TN) contents $(n=3)$ were determined using a Leco CHNS 932 analyzer. Bulk sediment porosity was determined on a known volume of sieved sediment used in the experiment. Grain size was determined by sieving a known amount of dry sediment through a stack of sieves with decreasing mesh size and re-weighing the amount collected in each sieve. Ninety-four percent of the sediment had a grain size between 100 and $500 \mu \mathrm{m}$ and the sediment was thus characterized as sandy.

\subsection{Experimental set-up}

There were three treatments ( $n=3): 1$ ) bioturbation by $M$. neglecta, 2) bioturbation by $H$. diversicolor, and 3) controls without animals. Nine transparent Plexiglas tube cores (height $50 \mathrm{~cm}$, inner diameter $8 \mathrm{~cm}$ ) were filled with $15 \mathrm{~cm}$ of sieved sediment and a $30 \mathrm{~cm}$ water column of filtered $(100 \mu \mathrm{m})$ brackish seawater. The sediment was inserted in the cores by pressing down the tubes in a bucket containing the sieved sediment and filling it with seawater to the top. A rubber stopper was then inserted at the top of the core and the tube was lifted out of the bucket, keeping the water and sediment inside by vacuum. Two more stoppers were immediately inserted at the bottom of the tube, first an inner stopper, fitting inside the tube and then an outer stopper in order to seal the tube. The sediment cores were left with aeration at $10^{\circ} \mathrm{C}$ for seven days before adding the animals. Sixteen $M$. neglecta and $4 \mathrm{H}$. diversicolor were added to each of the three replicate cores, respectively, and the remaining three were controls without worms. The number of worms of each species was chosen in order to have the same biomass per core (Table 2).

Worms were allowed to acclimatize and establish burrows for $7 \mathrm{~d}$ before the addition of luminophores. Batches of $2 \mathrm{~g}$ luminophores (63-125 $\mu \mathrm{m}$; Partrac Ltd., UK) were suspended in $20 \mathrm{~mL}$ of de-ionized water and poured into the water column of each core. The cores were left for $10 \mathrm{~d}$ with gentle aeration at $10^{\circ} \mathrm{C}$ and a $12 \mathrm{~h} / 12 \mathrm{~h}$ dark/light cycle. Bromide tracer was added to the cores at 3 separate occasions in order to have 3 different incubation times for each treatment, i.e. 1, 1.5 and $2 \mathrm{~d}$ before the end of the 10-day experiment (Martin and Banta, 1992). Before the addition of bromide, the water column in each core was adjusted to the same height $(10 \mathrm{~cm})$ and thus approximately the same volume (ca. $510 \mathrm{~mL}$ ). $\mathrm{NaBr}$ was dissolved in seawater and $10 \mathrm{~mL}$ of the stock solution was added to the overlying water of each core to reach a final concentration of ca. $10 \mathrm{mM}$. A $10 \mathrm{~mL}$ water sample from the overlying water column was taken 15 min after the initial bromide addition and stored at $4{ }^{\circ} \mathrm{C}$ until analysis.

Table 2

Animal additions to the experimental cores. Number of worms and biomass per core, length and width for individual worms. Average \pm STD.

\begin{tabular}{llllll}
\hline Species & $\begin{array}{l}\text { Number } \\
\text { of worms } \\
\text { per core }\end{array}$ & $\begin{array}{l}\text { Density } \\
\left(\text { ind. } \mathrm{m}^{-2}\right)\end{array}$ & $\begin{array}{l}\text { Length } \\
(\mathrm{mm})\end{array}$ & $\begin{array}{l}\text { Width } \\
(\mathrm{mm})\end{array}$ & $\begin{array}{l}\text { Biomass } \\
\text { per core } \\
(\mathrm{g} \text { ww) }\end{array}$ \\
\hline Control & - & - & - & - & - \\
Marenzelleria neglecta & 16 & 3200 & $35 \pm 10$ & $1.5 \pm 0.2$ & 2.2 \\
Hediste diversicolor & 4 & 800 & $93 \pm 17$ & $3.3 \pm 0.5$ & 2.4 \\
\hline
\end{tabular}




\subsection{Sampling}

All cores were sampled, in random order, $10 \mathrm{~d}$ after the addition of luminophores. First a $10 \mathrm{~mL}$ water sample was taken for bromide analysis. The overlying water was then siphoned off, leaving a few $\mathrm{mL}$ close to the sediment surface that were collected separately and saved for luminophore analysis. The outer bottom stopper was removed and the sediment was pushed up in the core using a piston, pressing on the inner bottom stopper, and sliced into $0.5-1 \mathrm{~cm}$ slices with a stainless steel blade. Slices of $0.5 \mathrm{~cm}$ were taken from the top $0-2 \mathrm{~cm}$ and then of $1 \mathrm{~cm}$ from 2 to $15 \mathrm{~cm}$. The time of sampling was carefully noted for each tube core in order to calculate the exact time of bromide incubation for each core. To prevent smearing effects of luminophores from surface layers to deeper sediment slices when pushing up the sediment in the core, a stainless steel cylinder of a slightly smaller diameter than the core $(7.7 \mathrm{~cm})$ was pressed over the slice and the sediment outside of the cylinder was removed. Each slice was weighed and then kept in plastic tubes with lids at $4{ }^{\circ} \mathrm{C}$ until centrifugation. The wet sediment was centrifuged at $800 \mathrm{rpm}$ for $6 \mathrm{~min}$ to extract the pore water, using double centrifuge tubes with a glassfiber filter (GF/F, Whatman) in the bottom of the inner tube. The extracted pore water from each slice was kept in air tight plastic tubes at $4{ }^{\circ} \mathrm{C}$ until bromide analysis. The remaining sediment of each slice was freeze-dried at $-20^{\circ} \mathrm{C}$ for ca. $100 \mathrm{~h}$ and weighed to obtain the dry weight. Porosity was calculated for each section of the sediment.

\subsection{Tracer analyses - luminophores and bromide}

Freeze-dried sediment from each slice was carefully homogenized and then sub-samples were taken for luminophore analysis. Counting of luminophores in each sample was done by placing the sediment under a UV-light and taking a digital photograph (Olympus C-2500L) followed by quantification using image analysis (software Image-Pro Plus).

Bromide concentration in the overlying water and pore water of each slice was determined spectrophotometrically by oxidizing bromide with chloramine-T in the presence of phenol red (Presley, 1971). Absorbance was measured at $595 \mathrm{~nm}$ and concentrations were calculated by fitting the absorbance to a standard curve (Schimadzu UV-1601).

\subsection{Modeling of particle-reworking}

The reaction-diffusion model used in this study to describe luminophore redistribution following macrofaunal reworking is based on the general diagenetic equation (Berner, 1980):

$\frac{\partial Q}{\partial t}=\frac{\partial}{\partial z}\left(D_{b} \frac{\partial Q}{\partial z}\right)+R(Q)$

where $Q$ is the quantity of the tracer, $t$ time from additions of the tracer, $z$ depth in the sediment ( $z=0$ at the water-sediment interface), $D_{b}$ the apparent biodiffusion coefficient, and $R(Q)$ the non-continuous displacement of tracer. The displacement is defined as follows:

$R(Q(z, t))=\left\{\begin{array}{l}\frac{r}{z_{2}-z_{1}} \int_{0}^{z_{1}} Q(x, t) d x \text { if } z \in\left[z_{1} ; z_{2}\right] \\ -r Q(z, t) \text { if } z \in\left[0 ; z_{1}\right] \\ 0 \text { if } z>z_{2}\end{array}\right.$

where $z_{1}$ and $z_{2}$ define the upper and lower limits of the tracer redistribution, $x$ and $z$ are depth variables, and $r$ (the non-local coefficient) the percentage of tracer that left the $\left[0, x_{1}\right]$ deposit and was redistributed in the $\left[z_{1}, z_{2}\right]$ layer. The redistribution of tracer between $z_{1}$ and $z_{2}$, and the disappearance of tracer from the $0-z_{1}$ layer, are described by Eqs. (2a) and (2b), respectively. Eq. (2c) denotes that no tracer movement occurs below the sediment depth $z_{2}$.

Non-local displacement of tracers was originally exemplified in a model describing gallery-diffusion of macrofaunal reworking (Francois et al., 2002). This biological reworking process describes the diffusivelike mixing of particles in the region of intense burrowing activity and the rapid transport of organic and inorganic material from the upper sediment layers to the lower regions of reworking.

According to the experimental conditions, the following initial conditions were used:

$Q(z, 0)=\left\{\begin{array}{l}Q_{0} \text { if } z \in\left[x_{1} ; x_{2}\right] \\ 0 \text { else }\end{array}\right.$

where $\left[x_{1} ; x_{2}\right]$ is the tracer deposit layer. Finally, a zero-flux Neuman boundary condition was considered:

$\frac{\partial Q}{\partial z}(0, t)=\lim _{z \rightarrow+\infty} \frac{\partial Q}{\partial z}(z, t)=0$.

Fitting our luminophore tracer redistribution data to this model using the least square method allowed us to estimate two parameters: the apparent biodiffusion coefficient $D_{b}$ and a non-local coefficient $r$. The biodiffusion coefficient $D_{b}$ takes into account the diffusion-like transport due to the activity of the organisms. We assume that the actual concentration dependent diffusion of tracers is negligible. The coefficient $r$ represents a non-local mixing pattern associated with a biologically induced transfer of particles from one place to another in a discontinuous pattern (i.e. a non-continuous transport; Boudreau, 1986; Meysman et al., 2003). The model was fitted to all cores individually.

\subsection{Net fluxes and biodiffusion coefficients calculated using bromide tracers}

The net bromide flux at the sediment-water interface, which is strongly affected by the pore water transport of solutes induced by the organisms (i.e. bioirrigation), was calculated by dividing the depth integrated total amount of excess bromide in the sediment pore water (mmol) over time (hours of incubation) with the bromide concentration in the overlying water $(\mathrm{mmol} / \mathrm{L})$.

The diffusivity of the bromide tracer in this sediment $\left(D_{s}\right)$ was estimated to $0.40 \mathrm{~cm}^{2} \mathrm{~d}^{-1}$, based on the molecular diffusivity of bromide in water at $10^{\circ} \mathrm{C}$ (Li and Gregory, 1974) and a constant porosity with depth of 0.41 . The measured bromide profiles were fitted using the least square method to a simple 1-dimensional diffusion model (Berner 1980), according to:

$\frac{\partial Q}{\partial t}=\frac{\partial}{\partial z}\left(D_{a} \frac{\partial Q}{\partial z}\right)$

With the boundary conditions: the flux equals zero at the interface (Eq. 6);

$\frac{\partial Q}{\partial z}(0, t)=0$

and, the tracer quantity goes to zero when depth goes to infinity:

$Q(z, t) \rightarrow 0$

The model-estimated parameter $D_{a}$ (apparent diffusion coefficient) describes the diffusion like transport of bromide into the sediment. If $\mathrm{D}_{\mathrm{s}}$ equals $D_{a}$ the observed bromide profile can be assumed to be the result of molecular sediment diffusion only, while if $D_{a}>D_{s}$ then there is an enhanced transport. 

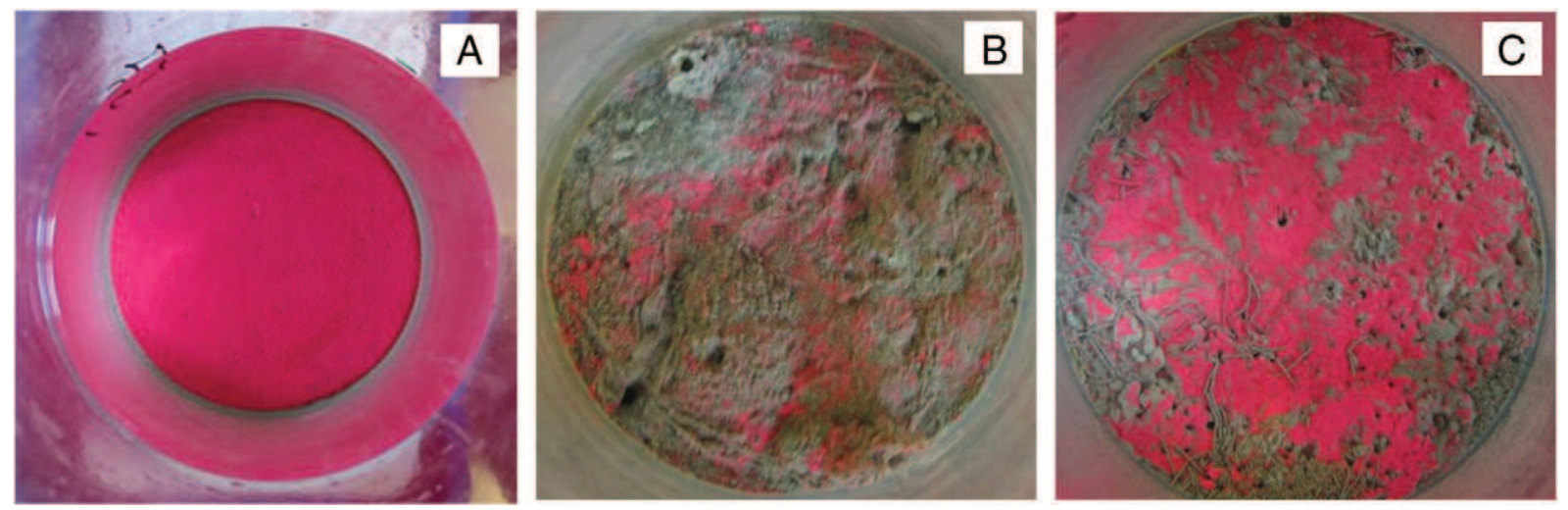

Fig. 1. Luminophores left at the surface after $10 \mathrm{~d}$ in A) control, B) Marenzelleria neglecta, and C) Hediste diversicolor cores.

\subsection{Statistics}

The luminophore data was analyzed using the Student's $t$-test comparing the difference in means between independent groups. When groups had unequal variances, a heteroscedastic $t$-test was performed. The bromide data was analyzed with a two-way repeated measurements ANOVA followed by a Tukey HSD post hoc test. Levene's test was used for verification of homogeneity of variance and Shapiro-Wilk's test for normality of data.

\section{Results}

\subsection{Sediment characteristics and visual observations}

Following addition to the cores, all worms rapidly buried into the sediment. Throughout the experiment new fecal pellets were regularly appearing at the sediment surface, indicating that the worms were in good conditions during the experiment. A successive depletion of luminophores was apparent for both species compared to the controls (Fig. 1) and burrows down to the bottom of the core, i.e. $15 \mathrm{~cm}$, were observed in all worm cores.

\subsection{Luminophore distribution}

Most of the luminophores (88-100\%) were found in the top $0.5 \mathrm{~cm}$ of the sediment at the end of the experiment in all treatments (Table 3). There was no significant difference in the percentage of luminophores recovered in the $0.5 \mathrm{~cm}$ between $M$. neglecta $(94 \%)$ and $H$. diversicolor $(87 \%, t$-test $p=0.14$ ). In the control cores, $100 \%$ of the luminophores were recovered in the top $0.5 \mathrm{~cm}$ layer. The depth of penetration, defined as the depth of $99 \%$ recovery of luminophores (Duport et al., 2006; Quintana et al., 2007), was ca. $6 \mathrm{~cm}$ for $M$. neglecta and $5 \mathrm{~cm}$ for $H$. diversicolor. Another way to quantify the depth of penetration of luminophores is to identify the deepest layer containing $>0.5 \%$ of the luminophores (maximum burial depth), since trace amounts of luminophores $(<0.5 \%)$ were found deep in all the bioturbated cores. The maximum burial depth of luminophores was $5 \mathrm{~cm}$ in all $H$. diversicolor cores and $1-1.5 \mathrm{~cm}$ in the $M$. neglecta cores (t-test $\mathrm{p}<0.01$, Table 3 ).
There was a good fit between the luminophore profile from experimental data and the profile obtained from the model (Fig. 2). The calculated biodiffusion coefficient, $D_{b}$, did not differ between the two species $\left(2.4 \times 10^{-3} \mathrm{~cm}^{2} \mathrm{~d}^{-1}, t\right.$-test $\left.\mathrm{p}=0.89\right)$ in the biodiffusive layer which was ca. $1-2 \mathrm{~cm}\left(0-z_{1}\right.$, Eq. (2)). However, the non-local coefficient, $r$, for $M$. neglecta was zero in all cores and $2.5 \pm 1.2 \mathrm{y}^{-1}$ in H. diversicolor cores (Table 3).

\subsection{Bromide transport}

In the control cores the sediment bromide profiles showed a steep decrease with depth and reached background levels at ca. 3-4 cm, irrespective of incubation time, indicating that molecular diffusion was the main transport process of bromide from the overlying water into the sediment in absence of bioturbation. This was confirmed by the good fit of the control core profiles with the 1D diffusion model when $D_{a}$ was set to $0.40 \mathrm{~cm}^{2} \mathrm{~d}^{-1}$ (1.5 d incubation, $\mathrm{r}^{2}=0.98$, Fig. 3 ), i.e. equal to the calculated molecular diffusivity, $\mathrm{D}_{\mathrm{s}}$, of bromide in this sediment. $D_{a}$ was $0.41\left(\mathrm{r}^{2}=0.96\right)$ and $0.25 \mathrm{~cm}^{2} \mathrm{~d}^{-1}\left(\mathrm{r}^{2}=0.96\right)$ in the 1- and 2-day incubations, respectively, and $D_{a}$ in the control cores was significantly different from the bioturbated cores (Tukey $\mathrm{p}<0.05$ ). Bioturbation by both worms rapidly increased the pore water concentration in the whole core, exceeding background levels even in the deepest layers after 1 day of incubation (Fig. 4). There was generally a good fit of the bromide profiles from both $M$. neglecta and $H$. diversicolor cores with the 1D diffusion model (Fig. 3). In the M. neglecta cores, $D_{a}$ decreased from $32\left(r^{2}=0.15\right)$ at day 1 to 15 $\left(\mathrm{r}^{2}=0.94\right)$ and $11 \mathrm{~cm}^{2} \mathrm{~d}^{-1}\left(\mathrm{r}^{2}=0.97\right)$ at 1.5 and $2 \mathrm{~d}$ of incubation, respectively (Table 4 ). The same pattern was observed in the $H$. diversicolor cores with the corresponding $D_{a}$ being $24\left(\mathrm{r}^{2}=0.82\right)$, $22\left(\mathrm{r}^{2}=0.12\right)$ and $10\left(\mathrm{r}^{2}=0.97\right)$. There were no differences in $D_{a}$ between the worm treatments (Tukey $\mathrm{p}>0.05$ ).

The calculated bromide fluxes were in agreement with the model results, i.e. a decreasing net flux (M. neglecta, H. diversicolor) with time of incubation, and no statistical difference between worms (Tukey $p<0.05$, Table 4). The average bromide net flux over time was $0.039 \pm$ $0.012 \mathrm{~mL} \mathrm{~min}^{-1}$ for $H$. diversicolor and $0.043 \pm 0.014 \mathrm{~mL} \mathrm{~min}^{-1}$ for M. neglecta.

Table 3

Recovery of luminophore tracers in the sediment at the end of the experiment $(10 \mathrm{~d})$ and modeled biodiffusion $\left(D_{b}\right)$ and non-local transport $(r)$ parameters. Average \pm STD.

\begin{tabular}{|c|c|c|c|c|c|}
\hline & \multirow[t]{2}{*}{$\%$ in $0.5 \mathrm{~cm}$} & \multirow{2}{*}{$\begin{array}{l}\text { 99\% depth mean (range) } \\
\mathrm{cm}\end{array}$} & \multirow{2}{*}{$\begin{array}{l}\text { Max burial depth }(>0.5 \% \text { in layer }) \\
\mathrm{cm}\end{array}$} & \multirow{2}{*}{$\frac{D_{b}}{\times 10^{-3} \mathrm{~cm}^{2} \mathrm{~d}^{-1}}$} & \multirow{2}{*}{$\frac{r}{\mathrm{y}^{-1}}$} \\
\hline & & & & & \\
\hline Marenzelleria neglecta & $94.1 \pm 1.4$ & $6(4-9)$ & $1-1.5$ & $2.4 \pm 0.2$ & 0 \\
\hline Hediste diversicolor & $87.5 \pm 6.1$ & $5(5)$ & 5 & $2.4 \pm 0.8$ & $2.5 \pm 1.2$ \\
\hline Control & 100 & 0.5 & - & - & - \\
\hline
\end{tabular}




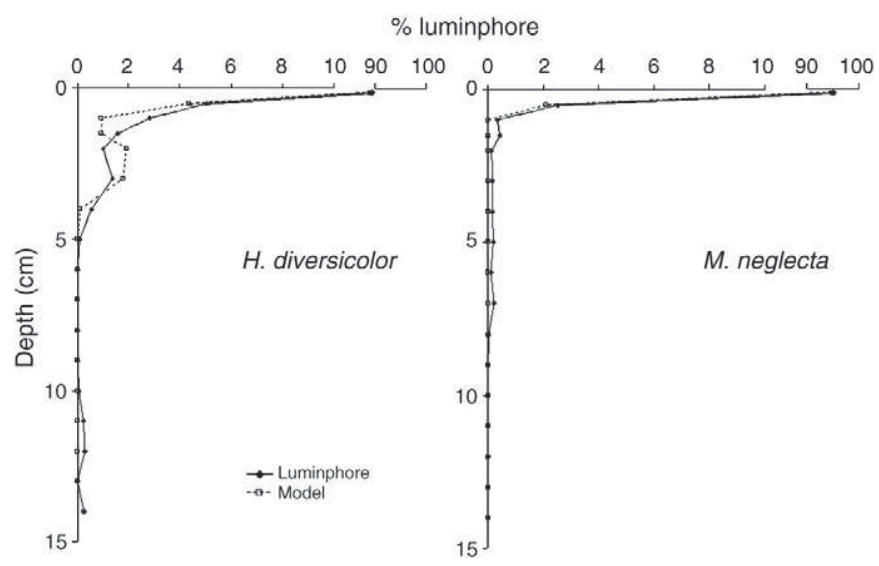

Fig. 2. Luminophore distribution in sediment (selected cores) after $10 \mathrm{~d}$ of bioturbation by Hediste diversicolor and Marenzelleria neglecta. Profiles show the percentage of luminophores recovered at each depth (luminophore) and the best fit of the gallerydiffusion model (model) (see text for details).

\section{Discussion}

\subsection{Particle reworking}

From visual observations it was clear that more luminophores remained on the surface in the $M$. neglecta cores than in the H. diversicolor cores. In average $13 \%$ of the luminophores were buried below the top $0.5 \mathrm{~cm}$ surface layer by $H$. diversicolor compared to $6 \%$ by $M$. neglecta, however they were not statistically different. $H$. diversicolor also buried significant amounts ( $>0.5 \%)$ of luminophores deeper into the sediment $(5 \mathrm{~cm})$ than M. neglecta $(1.5 \mathrm{~cm})$. The gallery-diffusion model used here (Francois et al., 2002) to quantify the rate of sediment-reworking showed a good fit with the experimental data for both species. This model describes a combination of a biodiffusive-like particle mixing in the upper sediment layer, generally displayed as an exponential decrease of luminophores with depth, and a non-local transport below, which is often shown as a sub-surface peak. The calculated biodiffusion coefficients $D_{b}$ did not differ between the two species $\left(2.4 \times 10^{-3} \mathrm{~cm}^{2} \mathrm{~d}^{-1}\right)$ indicating a similar mixing rate of the top $1-2 \mathrm{~cm}$ sediment. On the other hand, the model only detected non-local transport (below the diffusive layer) by H. diversicolor. Apparent biodiffusion in the surface layer is due to the movement and feeding of the worms, creation of new burrows, and a passive fall down of tracers in the burrow openings. Both polychaetes in this experiment are surface depositfeeders, actively searching for food particles around the burrow opening, mixing particles as they move in and out of the sediment (Scaps, 2002; Zettler et al., 1995). A higher density of burrows at the surface would theoretically increase the biodiffusive mixing, e.g. Duport et al. (2006) saw an increased $D_{b}\left(3.0\right.$ to $\left.5.5 \times 10^{-3} \mathrm{~cm}^{2} \mathrm{~d}^{-1}\right)$ with increasing density (144-1153 ind. $\mathrm{m}^{-2}$ ) of $H$. diversicolor. The density of $H$. diversicolor in this study was 4 times lower than that of $M$. neglecta, thus indicating that individually $\mathrm{H}$. diversicolor is more effective in the mixing of particles in the upper sediment layers. Non-local transport below the biodiffusive layer is the result of particle translocation within the burrow structures, egestion of fecal pellets and burrow maintenance. This type of particlereworking is well known for $H$. diversicolor. The worm makes U-shaped burrows that are branched in their upper part, which creates a gallery of burrows below the sediment surface (Scaps, 2002). The sub-surface peak often observed when studying particle transport by $\mathrm{H}$. diversicolor usually corresponds with the bottom of the galleries where the particletracer accumulates (Duport et al., 2006). Sediment profiles in this study showed a minor increase of the percentage luminophores between 2 and $4 \mathrm{~cm}$ in the $H$. diversicolor cores, and the model calculated a moderate non-local transport parameter $r$, of $2.5 \mathrm{y}^{-1}$. No such subsurface peak was visible in the M. neglecta treatments and $r$ was zero. The un-branched, more or less vertical burrows created by M. neglecta do not interact to create a network. Tubes do not protrude above the sediment surface and the burrow opening is small (1-2 mm) compared to the larger (3-4 mm) more crater-like holes made by H. diversicolor, which can explain less passive transport into the burrow structures by M. neglecta.

Compared to previous studies on particle reworking by H. diversicolor, results presented here are in the lower range. For example, Duport et al. (2006) reported ca. $75 \%$ recovery of luminophores in the top $0.5 \mathrm{~cm}$, and a $D_{b}$ and $r$ of up to $5.5 \times 10^{-3} \mathrm{~cm}^{2} \mathrm{~d}^{-1}$ and $19.5 \mathrm{y}^{-1}$, respectively, for densities and incubation times similar to this experiment. Francois et al. (2002) showed that the amount of tracer recovered in the top sediment layer decreased from $75 \%$ to $55 \%$ as a function of incubation time (15 vs. $30 \mathrm{~d})$ at the same density of $H$. diversicolor as here, and calculated $D_{b}$ between ca. 5 to $23 \times 10^{-3} \mathrm{~cm}^{2} \mathrm{~d}^{-1}$ and $r$ between 3 and $12 \mathrm{y}^{-1}$. Both studies used the same type of tracers and the same gallerydiffusive model as in our study.

So far, there is only one peer-reviewed published study on the efficiency of particle bioturbation by the polychaete genus Marenzelleria. Quintana et al. (2007) compared bioturbation by M. viridis and the sub-surface feeding polychaete $H$. filiformis, reporting significantly higher particle mixing by $M$. viridis than $H$. filiformis. The recovery of

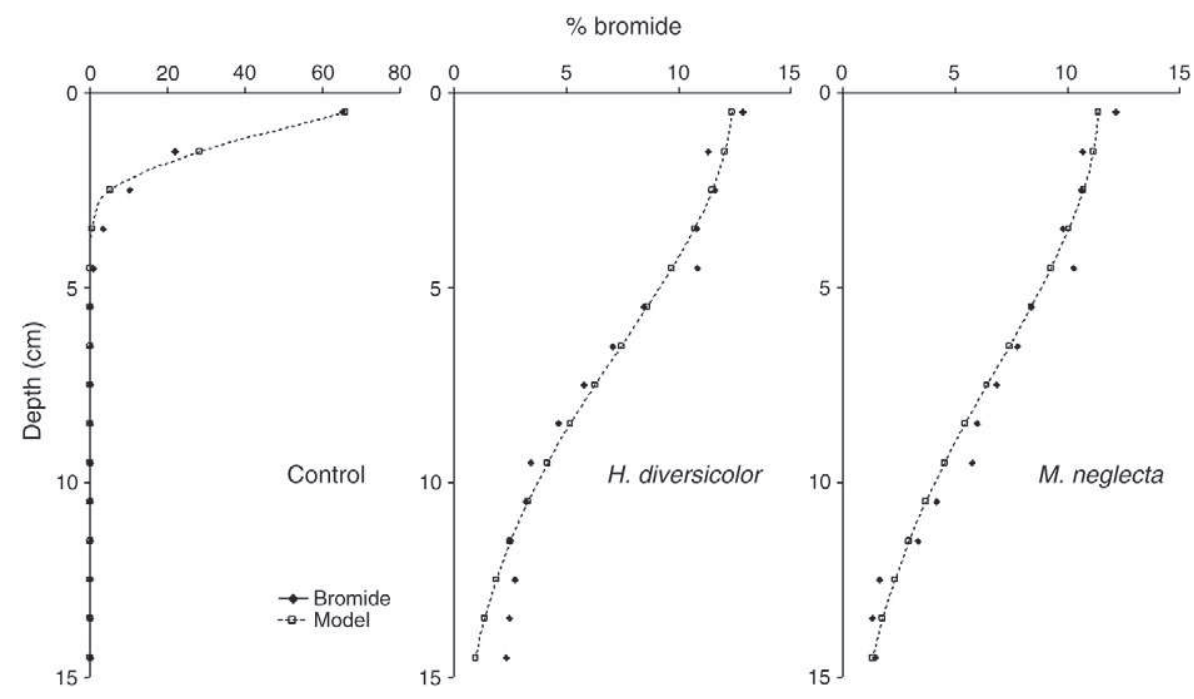

Fig. 3. Bromide in the sediment pore water after $2 \mathrm{~d}$ of incubation in cores with Hediste diversicolor, Marenzelleria neglecta or no fauna (control). Profiles show the percentage of the total pore water bromide inventory recovered at each depth (bromide) and the best fit of the 1D diffusion model (model) (see text for details). 


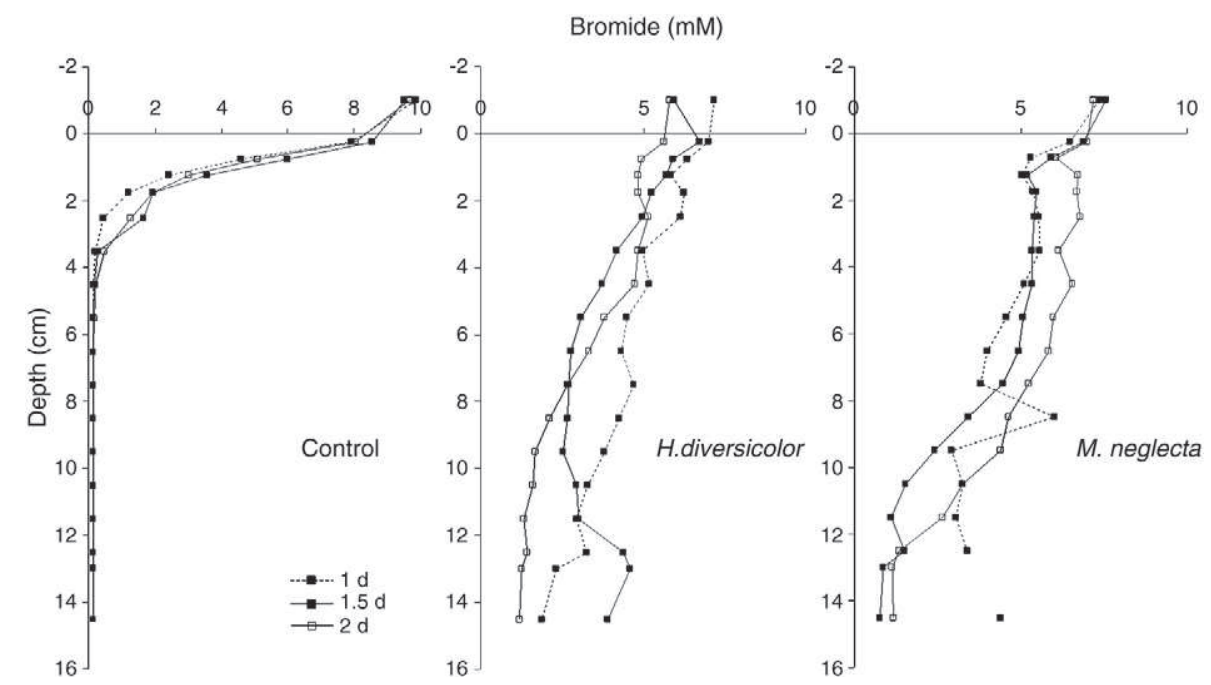

Fig. 4. Bromide pore water profiles ( $\mathrm{mM}$ ) and overlying water concentration ( $-1 \mathrm{~cm}$ on y-axis) at ca. 1, 1.5 and $2 \mathrm{~d}$ of incubation in cores with Hediste diversicolor, Marenzelleria neglecta or no fauna (control).

luminophores in the surface layer after bioturbation by $M$. viridis was between 75 and $80 \%$ and like in this study the sediment profiles showed a diffusion-like distribution of luminophores in the upper $1-2 \mathrm{~cm}$. A biodiffusion coefficient for $M$. viridis was calculated to $3.3-$ $4.0 \times 10^{-3} \mathrm{~cm}^{2} \mathrm{y}^{-1}$ using a 1-D diffusion model. The difference in $D_{b}$ between Quintana et al. (2007) and this study could in part be due to the choice of model; Francois et al. (2002) observed consistently slightly lower $D_{b}$ values obtained with the gallery-diffusion model than the simple biodiffusion model. In addition, the time of incubation in Quintana et al. (2007) was 3-4 times longer than here, which could have affected $D_{b}$ (Boudreau et al., 2001).

\subsection{Solute transport}

Fitting measured pore water profiles of solute tracers to a mathematical model is a common way of quantifying bioirrigation and a good tool for comparing the bioirrigation efficiency between treatments. Here we used a simple one-dimensional diffusion model, quantifying bioirrigation as an enhanced diffusion coefficient, $D_{a}$. Generally, there was a good fit between the measured and modeled bromide profiles, showing a diffusive-like transport of solutes into the sediment caused by the two polychaetes. The apparent diffusion rates $\left(D_{a}\right)$ were more than 40 times higher in the worm cores than in controls (molecular diffusion only). However, there was no difference between $M$. neglecta (11-32 $\mathrm{cm}^{2} \mathrm{~d}^{-1}$ ) and H. diversicolor (10$24 \mathrm{~cm}^{2} \mathrm{~d}^{-1}$ ). The progressively decreasing $D_{a}$ values with time of incubation is probably due to a decreasing concentration gradient (Meile et al., 2005).

Bioirrigation, i.e. pore water solute transport, is strongly coupled to the rate and mode of infaunal ventilation. $H$. diversicolor are known to be active bioirrigators (Kristensen and Hansen, 1999; Riisgård et al., 1992). They ventilate their burrows by pumping water uni-directionally through the U-shaped burrow, increasing the exchange of oxygen and metabolic products with the overlying water (Riisgård and Larsen, 2005), mainly through radial diffusion between the burrow and the pore water (Kristensen and Hansen, 1999). The diffusive-like bromide profiles in $\mathrm{H}$. diversicolor cores may therefore be due to a declining burrow density with depth. The blind-ended burrows created by $M$. neglecta, however, prevents a uni-directional circulation and thus advectively transported solutes within the burrow must either overcome the resistance and penetrate into the bulk sediment or be returned back to the overlying water through the burrow opening. Little is known about the burrow ventilation behavior of Marenzelleria spp., however, recently the ventilation mechanism of $M$. viridis was described, showing a combined ciliar and muscular pumping of water into and out of the burrow (Quintana et al., 2011). It was also suggested that bioirrigation is the result of eddy diffusion (advective transport) over the burrow wall and subsequent percolation through the bulk sediment back to the overlying water (Quintana et al., 2007; 2011). If the full length of the burrow is equally ventilated, it would result in a steep bromide profile throughout the bioturbated zone. The profiles in the M. neglecta cores tend to

Table 4

Enhanced biodiffusion coefficients $\left(D_{a}\right)$ and irrigation rates calculated using solute (bromide) tracer and various incubation times (ca. 1, 1.5 and $2 \mathrm{~d}$ ), and the estimated average individual and area-specific irrigation rates. Average \pm STD.

\begin{tabular}{|c|c|c|c|c|c|}
\hline & Incubation time & $D_{a}$ & Irrigation & Average individual irrigation & Average area specific irrigation \\
\hline & $\mathrm{h}$ & $\mathrm{cm}^{2} \mathrm{~d}^{-1}$ & $\mathrm{~mL} \min ^{-1}$ & $\mathrm{~mL} \min ^{-1}$ ind. $^{-1}$ & $\mathrm{Lm}^{-2} \mathrm{~d}^{-1}$ \\
\hline \multirow[t]{3}{*}{ Marenzelleria neglecta } & 27 & 32 & 0.059 & $0.003 \pm 0.001$ (ca. $135 \mathrm{~g} \mathrm{ww}$ ind. $^{-1}$ ) & ca. 12 (3200 ind. $\mathrm{m}^{-2}$ ) \\
\hline & 32 & 15 & 0.039 & & \\
\hline & 52 & 11 & 0.032 & & \\
\hline \multirow[t]{3}{*}{ Hediste diversicolor } & 31 & 24 & 0.049 & $0.01 \pm 0.003\left(\right.$ ca. $600 \mathrm{~g} \mathrm{ww}$ ind..$\left.^{-1}\right)$ & ca. 12 (800 ind. $\mathrm{m}^{-2}$ ) \\
\hline & 37 & 22 & 0.042 & & \\
\hline & 50 & 10 & 0.026 & & \\
\hline \multirow[t]{3}{*}{ Control } & 29 & 0.41 & - & - & - \\
\hline & 36 & 0.40 & & & \\
\hline & 53 & 0.25 & & & \\
\hline
\end{tabular}


be close to vertical down to ca. $6 \mathrm{~cm}$ depth (not including the top $0.5 \mathrm{~cm}$ layer, Fig. 4), which may indicate a similar mode of bioirrigation as proposed for $M$. viridis (Quintana et al., 2011). Burrows, however, were observed down to $15 \mathrm{~cm}$ depth. The decrease in bromide concentration below the more vertical zone could therefore be due to a declining burrow density with depth, but it may also be because the worms mainly occupy and ventilate the upper parts of their burrows. Observations made here and previously in the laboratory with Marenzelleria spp. have shown that they dig deep burrows $(>25 \mathrm{~cm}$ ) but largely remain close to the sediment surface.

The bromide net flux was also quantified by calculating the rate of bromide exchange between the overlying water and sediment. The average bromide net fluxes obtained were ca. $0.04 \mathrm{~mL} \mathrm{~min}^{-1}$ for both $H$. diversicolor and $M$. neglecta, corresponding to an area specific flux of ca. $12 \mathrm{~L} \mathrm{~m}^{-2} \mathrm{~d}^{-1}$. As the natural densities of $M$. neglecta is usually higher than that of $H$. diversicolor our results probably have good field relevance. When comparing bromide net fluxes between the treatments it is important to recognize the higher per individual rate in $H$. diversicolor $\left(0.01 \mathrm{~mL} \mathrm{~min}^{-1}\right)$ than in M. neglecta $\left(0.003 \mathrm{~mL} \mathrm{~min}^{-1}\right)$, meaning that at the same density $H$. diversicolor would probably have caused a higher flux than M. neglecta. However, there are densitydependent effects on organism behavior, including the frequency and intensity of ventilation, and an increase in faunal density usually results in a decrease in the individual flux (Matisoff and Wang, 1998; Reible et al., 1996). For example, it has been suggested that the flux is related to the square root of the total biomass (Forbes and Forbes, 1994; Reible et al., 1996). In addition, considering the considerably higher ventilation rates reported for $\mathrm{H}$. diversicolor (750$2700 \mathrm{~L} \mathrm{~m}^{-2} \mathrm{~d}^{-1}, 600$ ind. $\mathrm{m}^{-2}$ ) (Christensen et al., 2000) than for M. viridis (276 $\mathrm{L} \mathrm{m}^{-2} \mathrm{~d}^{-1}, 1200$ ind. $\mathrm{m}^{-2}$ ) (Quintana et al., 2011), the solute exchange efficiency (i.e. the amount of solutes transported into the pore water per volume of ventilated water) of $M$. neglecta was equal or higher than for $H$. diversicolor.

When discussing the ecological implications of the invasion of M. neglecta in the Baltic Sea, it should be noted that M. neglecta often inhabit muddy sediments in deeper habitats where $H$. diversicolor is not present. The mechanism of bioirrigation in sandy sediments differs from muddy sediments where the low permeability limits advective pore water transport. Instead molecular diffusion from the burrow is the primary mass transport mechanism (Shull et al., 2009). The solute exchange efficiency of $M$. neglecta is thus probably much lower in muddy sediments than what has been observed in this experiment. However, they dig deeper into the sediment than any of the native species in these habitats and thus the relatively high solute exchange deep in the sediment will significantly affect the sediment biogeochemistry in these sediments.

\section{Conclusions}

The two polychaete worms displayed similar particle-mixing and solute exchange efficiencies (based on total biomass) despite different modes of bioturbation. Generally, however, on an individual level $H$. diversicolor was a more efficient particle-reworker and M. neglecta a more efficient bioirrigator. This suggests that the ongoing colonization of nutrient rich and contaminated Baltic sediments by M. neglecta at high densities could lead to an enhanced soluble release of both nutrients and contaminants. In the frame of the Baltic Sea functioning, these results provide information about the potentialities of $M$. neglecta to modify sediment biogeochemistry when competing and/or replacing native species.

\section{Acknowledgments}

This study was funded by the Swedish Research Council Formas (grant nr 205-1424) and was part of the Nereis Park Experiment 07: "Sediment reworking by Nereidae species" (www.nereispark.org).
We thank A. Faarborg for help with bromide analyses, GT. Banta and S. Forster for discussions on Marenzelleria and bioirrigation, and J-C Poggiale for support on modeling. [ST]

\section{References}

Aller, R.C., 2001. Transport and reactions in the bioirrigated zone. In: Boudreau, B.P. Jørgensen, B.B. (Eds.), The Benthic Boundary Layer. Oxford University Press, Inc., New York, pp. 269-301.

Berner, R.A., 1980. Early Diagenesis: A Theoretical Approach. Princeton University Press, Princeton, NJ.

Blank, M., Laine, A.O., Juerss, K., Bastrop, R., 2008. Molecular identification key based on PCR RFLP for three polychaete sibling species of the genus Marenzelleria, and the species' current distribution in the Baltic Sea. Helgoland Marine Research 62, 129-141.

Boudreau, B.P., 1986. Mathematics of tracer mixing in sediments. 2. Nonlocal mixing and biological conveyor-belt phenomena. American Journal of Science 286, 199-238.

Boudreau, B.P., Choi, J., Meysman, F., François-Carcaillet, F., 2001. Diffusion in a latticeautomaton model of bioturbation by small deposit feeders. Journal of Marine Research 59 (5), 749-768.

Christensen, B., Vedel, A., Kristensen, E., 2000. Carbon and nitrogen fluxes in sediment inhabited by suspension-feeding (Nereis diversicolor) and non-suspension-feeding (N. virens) polychaetes. Marine Ecology Progress Series 192, 203-217.

Davey, J.T., 1994. The architecture of burrow of Nereis diversicolor and its quantification in relation to sediment-water exchange. Journal of Experimental Marine Biology and Ecology 179, 115-129.

Duport, E., Stora, G., Tremblay, P., Gilbert, F., 2006. Effects of population density on the sediment mixing induced by the gallery-diffusor Hediste (Nereis) diversicolor O.F. Muller, 1776. Journal of Experimental Marine Biology and Ecology 336, 33-41.

Forbes, V.E., Forbes, T.L., 1994. Integrated ecotoxicology: linking fate and effect within a biological hierarchy. In: Depledge, M.H., Sanders, B. (Eds.), Ecotoxicology in Theory and Practice. Chapman \& Hall, London, Glasgow, New York, Tokyo, Melbourne, Madras, pp. 149-183.

Francois, F., Gerino, M., Stora, G., Durbec, J.P., Poggiale, J.C., 2002. Functional approach to sediment reworking by gallery-forming macrobenthic organisms: modelling and application with the polychaete Nereis diversicolor. Marine Ecology Progress Series 229, 127-136.

Granberg. M.E Gunnarsson,JS. Hedman,JE. Rosenberg R. Jonsson, P., 2008. Bioturbationdriven release of organic contaminants from Baltic Sea sediments mediated by the invading polychaete Marenzelleria neglecta. Environmental Science and Technology 42 , 1058-1065.

Hedman, J.E., Bradshaw, C., Thorsson, M.H., Gilek, M., Gunnarsson, J.S., 2008. Fate of contaminants in Baltic Sea sediments: role of bioturbation and settling organic matter. Marine Ecology Progress Series 356, 25-38.

Hietanen, S., Laine, A.O., Lukkari, K., 2007. The complex effects of the invasive polychaetes Marenzelleria spp. on benthic nutrient dynamics. Journal of Experimental Marine Biology and Ecology 352, 89-102.

Kristensen, E., Hansen, K., 1999. Transport of carbon dioxide and ammonium in bioturbated (Nereis diversicolor) coastal, marine sediments. Biogeochemistry 45 , 147-168.

Kube, J., Zettler, M.L., Gosselck, F., Ossig, S., Powilleit, M., 1996. Distribution of Marenzelleria viridis (Polychaeta: Spionidae) in the southwestern Baltic Sea in 1993/94 - ten years after introduction. Sarsia 81, 131-142.

Leppäkoski, E., Gollasch, S., Gruszka, P., Ojaveer, H., Olenin, S., Panov, V., 2002. The Baltic - a sea of invaders. Canadian Journal of Fisheries and Aquatic Sciences 59, 1175-1188.

Li, Y.-H., Gregory, S., 1974. Diffusion of ions in sea water and in deep-sea sediments. Geochimica et Cosmochimica Acta 38, 703-714.

Martin, W.R., Banta, G.T., 1992. The measurement of sediment irrigation rates - a comparison of the Br-Tracer and Rn-222/Ra-226 disequilibrium techniques. Journal of Marine Research 50, 125-154.

Matisoff, G., Wang, X.S., 1998. Solute transport in sediments by freshwater infaunal bioirrigators. Limnology and Oceanography 43, 1487-1499.

Meile, C., Berg, P., Van Cappellen, P., Tuncay, K., 2005. Solute-specific pore water irrigation: implications for chemical cycling in early diagenesis. Journal of Marine Research 63, 601-621.

Meysman, F.J.R., Boudreau, B.P., Middelburg, J.J., 2003. Relations between local, non local, discrete and continuous models of bioturbation. Journal of Marine Research $61,391-410$

Orlova, M.I., Telesh, I.V., Berezina, N.A., Antsulevich, A.E., Maximov, A.A., Litvinchuk, L.F., 2006. Effects of non indigenous species on diversity and community functioning in the eastern Gulf of Finland (Baltic Sea). Helgoland Marine Research 60, 98-105.

Presley, B.J., 1971. Techniques for analyzing interstitial water samples. Part 1: determination of selected minor and major inorganic constituents. Initial Report of Deep Sea Drilling Project 7 (2), 1749-1755.

Quintana, C.O., Tang, M., Kristensen, E., 2007. Simultaneous study of particle reworking irrigation transport and reaction rates in sediment bioturbated by the polychaetes Heteromastus and Marenzelleria. Journal of Experimental Marine Biology and Ecology $352,392-406$.

Quintana, C.O., Hansen, T., Delefosse, M., Banta, G., Kristensen, E., 2011. Burrow ventilation and associated porewater irrigation by the polychaete Marenzelleria viridis. Journal of Experimental Marine Biology and Ecology 397, 179-187.

Rasmussen, E., 1973. Systematics and ecology of the Isefjord marine fauna (Denmark) Ophelia $11,1-507$ 
Reible, D.D., Popov, V., Valsaraj, K.T., Thibodeaux, L.J., Lin, F., Dikshit, M., Todaro, M.A. Fleeger, J.W., 1996. Contaminant fluxes from sediment due to tubificid oligochaete bioturbation. Water Research 30, 704-714.

Riisgård, H.U., Larsen, P.S., 2005. Water pumping and analysis of flow in burrowing zoobenthos: and overview. Aquatic Ecology 39, 237-258.

Riisgård, H.U., Vedel, A., Boye, H., Larsen, P.S., 1992. Filter-net structure and pumping activity in the polychaete Nereis diversicolor - effects of temperature and pumpmodelling. Marine Ecology Progress Series 83, 79-89.
Scaps, P., 2002. A review of the biology, ecology and potential use of the common ragworm Hediste diversicolor (OF Muller) (Annelida: Polychaeta). Hydrobiologia 470, 203-218.

Shull, D.H., Benoit, J.M., Wojcik, C., Senning, J.R., 2009. Infaunal burrow ventilation and porewater transport in muddy sediments. Estaurine, Coastal and Shelf Science 83, 277-286.

Zettler, M.L., Bick, A., Bochert, R, 1995. Distribution and population dynamics of Marenzelleria viridis (Polychaeta, Spionidae) in a costal water of the Southern Baltic. Archive of Fishery and Marine Research 42, 209-224. 